\title{
The Career Development of the International Students from the Countries of the Belt and Road Initiative: A Study Based on Grounded Theory
}

\author{
Qiaoyin Peng ${ }^{1} \&$ Yahui $\mathrm{Hu}^{1}$ \\ ${ }^{1}$ School of Economics and Management, LeShan Normal University, LeShan, Sichuan Province, China \\ Correspondence: Yahui Hu, School of Economics and Management, LeShan Normal University, No.778, Binhe \\ Road, LeShan City, Sichuan Province, China. E-mail: 765202104@qq.com
}

Received: May 7, 2020 Accepted: June 12, 2020 Online Published: June 20, 2020

doi:10.5539/jel.v9n4p72 URL: https://doi.org/10.5539/jel.v9n4p72

\begin{abstract}
Focusing on the phenomena of low person-post matching, professionalism mismatching and talents potential deficit emerging in the development process of the international students from the countries of the Belt and Road Initiative, this paper adopted the Grounded Theory as the research method and investigated the employment units along the routes, the employed international students who returned homeland as well as those who stayed in in China. Subject analysis, open coding and selective coding were applied as analysis methods to construct the mode of factors affecting career development of the international students in China. Based on the results, the author suggested that universities and colleges attach greater importance to career education of the Belt and Road Initiative international students in China, explore and set up a career development education system and occupational exploration platforms for countries along the route, develop a curriculum platform closely combined with Chinese culture, and build up a practical platform suitable for international students.
\end{abstract}

Keywords: the Belt and Road Initiative, international students in China, career success, career development

\section{Introduction}

In order to build up a global community of political mutual trust, economic integration and cultural intolerance, China contributed an enormous sum of investment to infrastructure construction of the countries of the Belt and Road Initiative and the demand of talents in enterprises has been gradually increasing ever since. However, at present, the talent development in those countries shows obvious unbalance and mis-match, and facts such as low person-post matching, professionalism mismatching and talents potential deficit have greatly restricted the progression of the enterprises, and profoundly affected the depth and breadth of the high-quality development of the Belt and Road Initiative. To achieve the high-quality development of the strategy, the Plan for International Students in China issued by the Ministry of Education in 2010 pointed out that, China would become the largest destination of overseas study in Asia in 2020. At the National Meeting of Studying Abroad held in 2014, President Xi Jinping highlighted that the work of study abroad plan was supposed to adapt to the overall development trend of the country, the general policies of the Communist Party of China (CPC) and government.

Since 2010, the researches on the education for the international students from the countries of the Belt and Road Initiative has become a hotter project than ever before, and a great number of graduated international students have gradually returned home and devoted themselves into the local economic construction. However, among those conducted researches, few have studied from the aspect of the career development of international students. It seems impossible to accomplish a fundamental improvement of continuous economic growth of the countries along the route and high-quality education for international students studying in China unless the career education to those oversea students is provided. Based on the existing studies, this research attempted to extract a series of variables related to the career success of the international students by adopting the Grounded Theory as the study method, set out various types of career-impact models concerning with the career success values of the international students, so as to provide them with theoretical and practical instructions of the career education. 


\section{Theoretical Basis and Research Background}

\subsection{Social Cognitive Career Theory}

In the Social Cognitive Career Theory (SCCT), individual difference, environmental factors and behavior by interacting each other can have impacts on the individual career development, including vocational interests, vocational targets and vocational values etc. (Lent \& Brown, 1996). Therefore, this research all along focused on three perspectives, individual characters, social environment and individual behaviors, in the course of exploring the career development of the international students in China. According to the research of personality traits in the field of occupation, the study of vocational interests, vocational personality and vocational values need to be conducted from the perspective of individual inherence, while in the research of the external occupational environment, the external environment is necessary to be analyzed before exploring the suitable occupations. Lee et al. (2016) put forward that the turning of the exploratory behavior of inner traits and external environment to the occupational exploration was a vital behavior to develop the vocational ability and achieve the career objectives. After the document research on occupational exploration, it could be found that scholars concentrate on proving the behavior of occupational exploration has effect on the short-term or long-term occupational consequence from the perspectives of the career decision-making, interview chances and employability, salary, job satisfaction, work efficiency and occupational well-being etc. (Cheung \& Jin, 2016). Hence, by adopting the qualitative research approach, this research attempted to reveal the effect variables of occupational exploration caused by social culture, families and overseas studying experience.

\subsection{Construction Theory of the Clearness on Career Success}

In view of the current situation and changes of the education for the international students (Zhu \& Hu, 2018), many problems of the research on the higher education of the Belt and Road Initiative have been discovered: the lack of research depth and breadth, insufficiency of research connectivity and inadequacy of combination of macro and micro researches. Therefore, universities and colleges should put more efforts in discipline construction, innovative mode of talent training and the improvement of education. The export of talents cultivation determines the quality of the development of the higher education nationalization in China, and the attitudes, interests, as well as focuses toward occupational options of the international students, play a vital role in their education. The studies on the view of occupational success have always been a hot topic in the field of career research. Based on the view of career success, Xin el al. (2019) extracted a new concept of the clearness on occupational success from the perspective of constructivism, and proved the impact of the personality traits and exploration behaviors have on the value of success. The research also tested the moderation effect of family income and the occupation level of the mothers, and the activation of environment factors on personality traits were validated in the field of career development. The development research of trait activation theory was applied to the international students in China to form more specific and practical schemes for the career guidance to those in universities and colleges, to help the career guidance department in universities and colleges to adjust the career-selection stage from the perspective of occupation exploration, thus to fully exert the personality trait of individual initiative for the career selection stage of career guidance.

\subsection{Chinese Culture Under the View of International Students Education in China}

Based on the ideological and political management viewed under the perspectives of coordinated management, service optimization, cultural transmission in the cultural marketing of international students, Chen and Wen (2015). Chen and Wen (2015) proposed a talent cultivation plan for the international students in China according to the industrial characters, talent demanding as well as educational characteristics of universities and colleges in China, Ren and other scholars put forward a four-in-one innovative talent-training goal for the international students, which can achieve the targets of "innovative thinking ability, specialized knowledge and ability, practical ability as well as communication ability". From the cross-cultural perspective of international students in Beijing universities, Wang (2016) analyzed their behaviors based on the aspects of language, life, psychology and culture. Other aspects such as the motivations that the international students have of coming to China and their career development after graduation has been studied, and their economic behavior was also taken into account by some researchers. Through analyses, it can be found that cultural transmission and interaction are the crucial behaviors of the Belt and Road Initiative and this research attempted to predict the subjective and objective occupational success after receiving the Chinese cultural education.

\subsection{Proposal of the Research Questions}

Based on the Social Cognitive Career Theory, what are the key dependent variables of occupational exploration of overseas students in China? What are the differences between the variables and how to define as well as compare them? Which variables are related to factors of the international cultural exchanges and what profound 
impacts are produced on the great power diplomacy of China? How to reasonably and properly conduct career guidance through the education for the international students from the countries of the Belt and Road Initiative and facilitate their high-quality educational development?

\section{Research Methods}

\subsection{Research Samples}

Grounded Theory research method is a kind of qualitative research method. Before the research, researchers generally have no theoretical hypothesis. They directly start from the actual observation, summarize the experience overview from the original data, and then rise to the systematic theory. This is a way to establish the essence theory from the bottom up. It is the core concept of finding the essence of things on the basis of systematic data collection (Strauss, 1987, p. 5).

This research selected samples of the international students in China out of the following considerations: Occupational development is related to the measurement of external and internal dimensions. In essence, it is a process of internal self-reconstruction of individuals combining with external working environment and social environment. Most of the international students with the background of the Belt and Road Initiative are coming from the Southeast Asian countries with relatively backward economic development. Their determination of occupational success is influenced by the local economic and cultural factors. Meanwhile, the deep exploration of individual occupation and the pursuit of meaning are based on the cognition of social environment. The international students in China pay more attention to not only the depth and breadth of the influence of Chinese culture but also the degree of their recognition of Chinese culture when they make choices for occupational development.

The characteristics of samples are as follows: Within 3 years after graduation, some international students returned to their home countries and others chose to stay in China to work. Employers have employed overseas students in China, including local domestic enterprises, local foreign companies and domestic enterprises.

This study selected 21 international students in China, who are coming from Laos, Vietnam, and Myanmar, 4 local companies and 6 Chinese expatriate companies in Laos and Vietnam, and 6 companies that have employed international students in China. A total of 21 graduate students and 16 representatives of employers participated. Considering the quality research lays emphasis on the depth and breadth of the samples, all the interviewees are the international students graduated in China or the enterprises from countries from the Belt and Road Initiative, and the graduation periods of the interviewed students are no more than 3 years to ensure their thinking and memories about difficulties during the employment process are clear and easier to recall. All units and individuals participating in the survey follow the principle of voluntary participation.

\subsection{Data Collection}

The initial data lasted from September 2018 to January 2019. The first group, 10 international students who have graduated from China, were recruited to discuss their understandings about personal career success. The structured interview outline was designed, which mainly included the following major questions: in your opinion, what kind of job do you consider successful? What kind of job do most people think is a sign of success in your country? How does professional education during your study in China affect your career development? What kind of contents of professional education, Chinese culture and career development have greater impacts on your career development and why? Combining with the views on career success, the interviewees were asked to recall the development of studying in China. The second group contains 8 employers, including 5 companies that the researchers interviewed in Laos and Vietnam. The outline of the structured interview mainly includes: What do you value most about working as an international student? What is the greatest impact of studying in China on their working? What do you think are the main differences between this group of employees and others? What do you hope for their career development? Each sample of the above interviews lasted for 1-3 hours. All the interviews were recorded and 13 of the recordings were converted into manuscripts. 5 interviewees were unwilling to be recorded during the interview. The research team took notes in time during the interview, and completed the memo in 8 hours after the interview. Based on this, the recordings, notes, text and pictures of the interview constitute the data source.

\subsection{Data Analysis}

This article used the data-coding method of the Grounded Theory and through open coding, the theme of occupational success view was gradually generated. After which, the clearness of the occupational success view was compared based on social cognitive career theory. Through deep substantive coding and theoretical coding, this research gradually discovered the unique order and structure of occupational success view that possessed by 
the international students in China behind the social cognitive career theory, and generated the definition and category of relevant variables.

In the process of data analysis, this article on the one hand classified and refined each part of the data related to the clearness of the occupational success view according to the available data provided by the existing researches and generated new codes one by one on the coding memo. On the other hand, the interview data were classified, defined and coded with 210,000 words of barcode, and through the three stages of selection and comparison, the generated codes were kept clear.

\subsubsection{The Stage of Open Coding}

This research compared and decomposed the large amount data sentence by sentence, and assigned corresponding labels to the actions as well as time of the interviewees had during the college years. A total of 160 items were collected which can reflected the problems that the international students in China encountered during the occupational process. Thorough conceptualization, a total of 173 and 6 different categories were obtained, and the summaries are as follows:

Table 1. Concept and category of open coding of career success factors for the international students from the countries of the Belt and Road Initiative (representative content)

\begin{tabular}{llll}
\hline Number & Data logging & Open coding & Conceptualization \\
\hline 21 & $\begin{array}{l}\text { The theatrical performances I took part in during my } \\
\text { college years made me more confident in employment } \\
34\end{array}$ & $\begin{array}{l}\text { Psychological and } \\
\text { I just wanted to find a job where I can make money. I'm } \\
\text { making three times the local average } \\
\text { My travel experience during studying abroad enabled me } \\
\text { to work in enterprises and make many friends } \\
\text { Income treatment }\end{array}$ & A2 Cultural exploration \\
& $\begin{array}{l}\text { The skill trainings I participated in during the internship } \\
\text { helped me a lot in my work }\end{array}$ & Internship and practice & A2 Cultural exploration \\
32 & $\begin{array}{l}\text { I think the sports I took part in at university made me } \\
\text { useful in my work }\end{array}$ & $\begin{array}{l}\text { Psychological and } \\
\text { Physical exercise } \\
\text { My parents insisted that I should return to work, and my } \\
\text { language communication skills acquired during the time } \\
\text { studying abroad enabled me to find a good job }\end{array}$ & A2 Cultural exploration \\
& & A2 Cultural exploration
\end{tabular}

Note. What the table captures are only parts of the whole.

\subsubsection{After the Open Coding}

Axial coding was further constructed according to the definition of the career success concept. During the coding process, it was found by continuous summaries that the influencing factors for the occupational development of the international students in China were from different subject ranges and were basically determined as three major categories.

From the perspective of professional development, it was found that the words, such as education, skills, qualifications, internships, often used by the interviewees during the coding process were the ways that international students wished to learn through the experience of studying abroad, while some international students also claimed that it did not matter what the majors were as long as they could learn Chinese well. 
Table 2.Typical relationship structure of the main category of professional development factors for the international students from the countries of the Belt and Road Initiative

\begin{tabular}{lll}
\hline Major category & Categorization & Original concept \\
\hline $\begin{array}{l}\text { Professional } \\
\text { development }\end{array}$ & Professional skills & A13 accounting ability A19 computer ability A27 tour guide method A28 \\
factors & & $\begin{array}{l}\text { communication in Chinese A29 e-commerce A30 business negotiation A50 } \\
\text { international trade A51 marketing A55 financial accounting A56 management } \\
\text { ability }\end{array}$ \\
& & A14 junior college A17 bachelor degree A18 further education A31 poor education \\
& background A21 high academic qualification \\
& Qualification certificate & A16 Accounting Certificate A15 Chinese Certificate \\
& & A24 Financial Qualification Certificate A25 Human Resources Management \\
& Certificate A26 Driving License \\
& A20 internship in the company A23 internship week A52 Jing Dong training A53 \\
& part-time jobs A54 internship in the company to accumulate experience A internship \\
\hline
\end{tabular}

From the perspective of cultural exploration factors, words such as tourism, food, attractions, history, and etiquette are mainly mentioned in the coding process. It can be seen that the learning experience of the international students in China are mainly through in-depth understanding of Chinese culture to form an occupational plan.

Table 3.Typical relationship structure of the main category of cultural exploration factors for the international students from the countries of the Belt and Road Initiative

\begin{tabular}{lll}
\hline Major category & Categorization & Original concept \\
\hline Cultural exploration & Culture and sports & A3 flower arrangement competition A12 dance competition A32 aerobics A33 singing \\
factors & & A42 class performance A43 dormitory culture festival A club activity A welcome party \\
& A61 Top Ten singers A62 football match \\
& A41 Climbing Mount Emei A4 Backpacker A9 Cycling A10 Free Walking A11 \\
& Attractions \\
& Food culture & A5 malatang A7 Hot Pot A8 chuanchuanxiang A34 beancurd jelly A40 Light A60 \\
& Canteen A Snack A58 Restaurant A57 Braised Meat A38 Pasta A39 Sichuan Cuisine \\
& Etiquette culture & A37 public places A6 dining etiquette A59 time concept A35 respect for the elderly and \\
& & \\
& &
\end{tabular}

From the perspective of career development factors, words such as making money, industry, business and practical are mainly mentioned in the coding process, which chiefly reflected the consideration generated by selection confusion during the process of job pursuing of the international process. The codes focus on the needs of the employers in the practical process of international students.

Table 4.Typical relationship structure of the main category of career development factors for the international students from the countries of the Belt and Road Initiative

\begin{tabular}{lll}
\hline Major category & Categorization & Original concept \\
\hline Career development & Employment industry & A2 Tourism A65 Real estate A66 Tour guide A72 Translation A71 accounting A70 \\
factors & & Legal A69 Contract A68 Sino-foreign joint venture A67 Chinese enterprises \\
& Career planning & A1 Foreign-funded enterprise A45 Management A46 Money-making A63 Resignation \\
& & A64 Post change \\
& \multirow{2}{*}{ Industrial development } & A47 Financial needs A48 Real estate development A49 Family enterprise A Civil \\
& & servant A Sino-foreign joint venture \\
\hline
\end{tabular}

3.3.3 Selective Coding: A Model of Factors Influencing the Career Development of International Students in China

The purpose of selective coding is to deal with the relationship between categories in a systematic way, so as to make their internal logic and relevance concrete. In this stage, we need to dig out the core categories from the main categories, analyze the logical relationship between the core categories and other categories, and summarize various related variables into the theoretical framework in the form of story lines. In this study, three main 
categories are obtained through the axial code, and the core categories that influence the career development of international students in China are professional development, cultural experience and career development. Therefore, a model of factors influencing the career development of international students in China is constructed. In this study, it is found that the category of "influencing factors of career development of international students" is used to analyze other categories and concepts. Therefore, the story line around this core category is "profession, culture and environment".

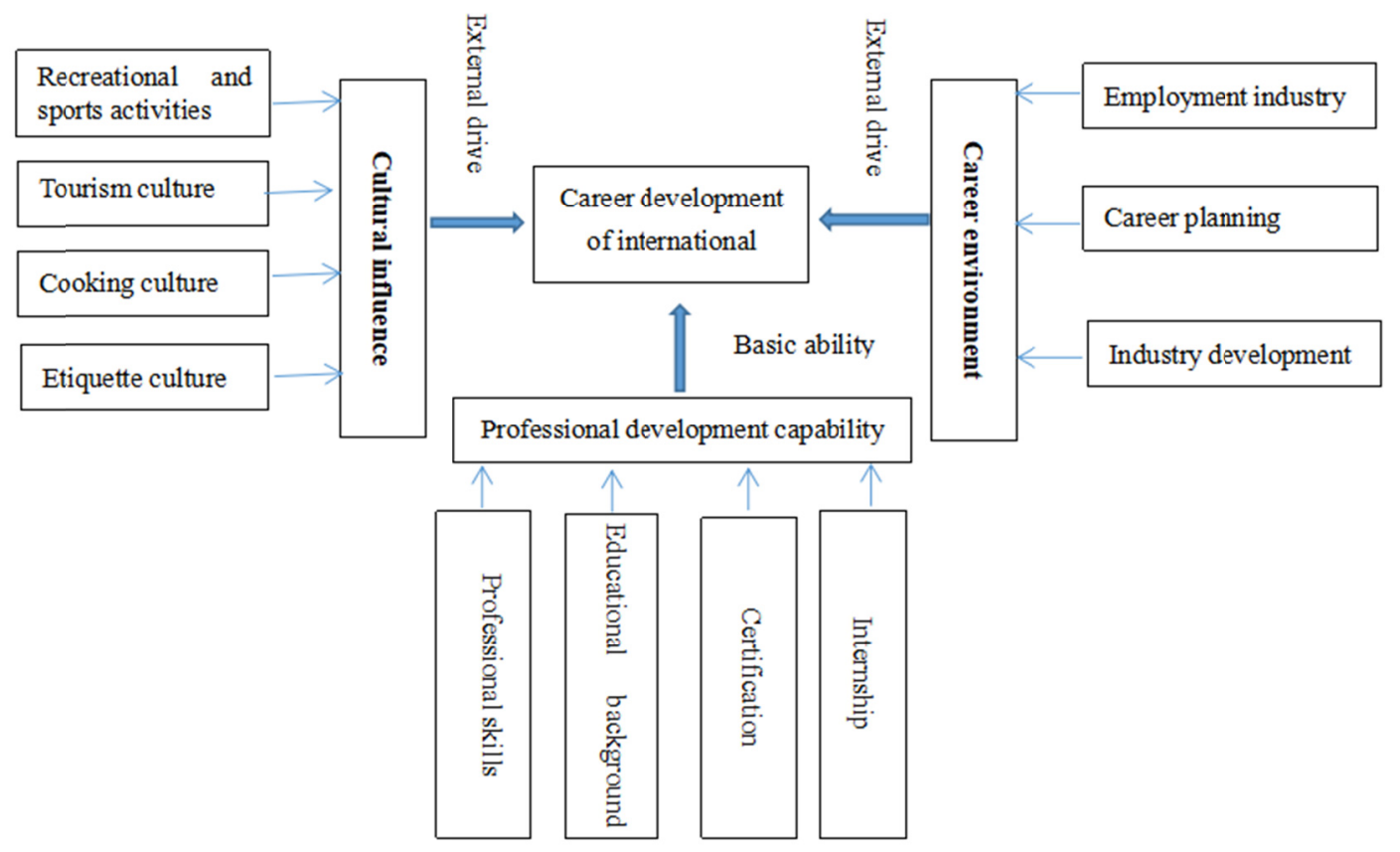

Figure 1. A model of factors influencing the career development of international students in China

\section{Conclusion Analysis and Countermeasure Suggestion}

The model of "profession, culture and environment" explains the factors of the career development of international students in China. The basic relationship is that the three main categories of "profession, culture and environment" have significant influence on the career development of international students in China, but the influence mechanism of the main categories is different.

"Profession and career development" explains that professional ability is the basis of career development. Four guarantees, professional skills, education promotion, qualification examination and internship, are important factors affecting professional ability. "Culture and career development" explains the influence of international students' cultural learning in foreign countries on career development. And the participation of cultural and sports activities, tourism activities, catering culture, etiquette culture deeply influences the ability of career development, and the participation degree of different factors has different influence on career development. "Environment and career development" explains the influence of the professional environment atmosphere, professional development trend and industrial development from home country and China on the professional ability of international students.

This study focuses on "what factors can affect the career development of overseas students in China?" Based on the Grounded Theory, this paper conducted in-depth interviews with overseas students in China, and established a model of influencing factors for the career development of international students in China, including three main categories of "profession, culture and environment", involving 11 sub-categories, and found the relationship among basic ability, external drive and internal drive in depth.

Through this study, the following suggestions are offered to international students of the countries from the Belt and Road Initiative: 


\subsection{Attach Importance to Professional Learning and Cultivate Active Learning Ability}

On the basis of the excellent assistance conditions of study provided by China, international students should take a long-term perspective and combine the actual conditions of the country they stay in to strengthen professional learning, improve the level of professional internationalization and master the solid professional knowledge by participating activities of practice and professional skills, thus to be able to play an active role in the future development of the country.

\subsubsection{Strengthen the Cultural Exploration and Learn from the Chinese Experience}

After thousands of years of accumulation and inheritance of Chinese culture, China's economic development has grown through twists and turns and achieved world-renowned achievements. The international students should participate in local cultural activities as much as possible during their stay in China, and acquire a deep understanding towards the past and present development of China through traveling, food experience, and extensive reading. In this way, the international students could gradually form their own perceptions of Chinese experience, which would also promote their awareness of career cognition after returning to their home countries.

\subsubsection{Pay Attention to Targeted Professional Experience}

Although international students are limited by strict legal requirements in pursuing the part-time jobs in China, they should still participate in internship training, professional practice and other activities organized by the school as much as possible. In spare time, they can visit Chinese enterprises to understand their needs and laws of development, so that they could make a career development plan earlier after returning.

\subsection{Suggestions on Career Education for the International Students from Countries of the Belt and Road Initiative of in China}

\subsubsection{Attach More Attention to the Career Education for Those International Students in Chinese Universities}

In the future, the career education for international students in China will be developed at the level of national strategy. It can promote the realization of high-quality employment of person-post matching and better accomplish the Study in China Plan once the career education is involved in the talent training program designed for the international students in universities, and the system of career education for international students can be gradually established.

\subsubsection{Explore and Set up a System of Career Education for International Students}

Universities and colleges should take actual conditions into consideration, gradually build up a career education system in accordance with situations of the nation, school and students; organize the "career consultations" and group-targeted "career guidance" that are suitable for the international students.; build career consultation rooms, development rooms of occupational psychological quality, career assessment rooms, training camps of group counseling, career planning studios and pre-service simulation training rooms etc., so as to provide career planning consultation for the international students in China. Besides, universities and colleges should guide them to correctly realize the relationship between the experience of studying abroad and career development, scientifically analyze the employment information, carry out proper career exploration, and assist them to accurately identify their professional interests and professional values.

\subsubsection{Explore and Establish Occupational Platforms for Countries Along the Belt and Road Initiative}

During the implementation of the project, the toughest problem was that the collection of occupational information in the countries along the route. To achieve high-quality talent training for international students, it is essential to the settle down the ways of the import and export of overseas students. By designing official websites providing career planning and consultation, information-release platforms and recruitment websites etc., internationally interconnected employment information platforms, multi-channel and diverse employment information release channels are set up to tackle the disconnection between talent training and using of international students.

4.2.4 Develop a Platform for the Curriculum of Career Development for International Students, Closely Combined with "Chinese Culture plus Career Planning"

According to verification and research, it was found that the identification of Chinese culture of the international students is the crucial influence of their career development. Therefore, universities and colleges can actively develop some basic courses of career development combining with Chinese tourism, diet, clothes and trade, and embed them into compulsory lessons of the international students, which can facilitate them comprehensively understand Chinese culture and better build their visions of occupational development. 


\subsubsection{Build up Professional Practice Platforms Suitable for International Students}

Actively strive for support offered by Chinese enterprises, the home-country enterprises and tutors inside and outside the universities and colleges, provide practical platforms for international students, and jointly build an integrated platform for innovation and entrepreneurship. In addition, a fully capable platform with strong social interaction and great practical effects is needed to be constructed, so as to enrich their experiences before returning to their home countries for employment.

\section{Acknowledgments}

This paper is sponsored by 2018-2020 years' higher education quality and teaching reform in Sichuan Province: "Internet +" Innovation and Entrepreneurship Project.

\section{References}

Chen, Q., \& Wen, W. (2018). "The Belt and Road Initiative": the education for international students in China: Mission, Challenges and Countermeasures. Journal of Higher Education Management, 12(03), 28-33.

Cheung, R., \& Jin, Q. (2016). Impact of a Career Exploration Course on Career Decision Making, Adaptability, and Relational Support in Hong Kong. Journal of Career Assessment, 24(3), 481-496. https://doi.org/10.1177/1069072715599390

Lee, B., Porfili, E. J., \& Hirschi, A. (2016). Between- and Within-Person Level Motivational Precursors, Associated with Career Exploration. Journal of Vocational Behavior, 92, 125-134. https://doi.org/10.1016/j.jvb.2015.11.009

Lent, R. W., \& Brown, S. D. (1996). Social Cognitive Approach to Career Development: An overview. Career Development Quarterly, 44(4), 310-321. https://doi.org/10.1002/j.2161-0045.1996.tb00448.x

Wang, Z. (2016). An empirical study on intercultural adaptation of international students in Beijing Universities. China Higher Education Research, 01, 91-96.

Xin, L., Zhou, W. X., \& Tang, F. C. (2019). The antecedent variable of the definition of career success value and its mechanism-from the perspective of social cognitive career theory (SCCT). Business Management Journal, 4, 127-138.

Zhou, W. X., Xin, X., \& Pan, J. Z. (2015). Capital of career success: building a comprehensive model of the factors influencing career success at the individual level. Journal of Higher Education Management, 17, $38-45$.

Zhu, H., \& Hu, J. G. (2018). A literature review on the education for overseas students in China in the past decade. China \& the World Cultural Exchange, 17(03), 28-33.

\section{Copyrights}

Copyright for this article is retained by the author, with first publication rights granted to the journal.

This is an open-access article distributed under the terms and conditions of the Creative Commons Attribution license (http://creativecommons.org/licenses/by/4.0/). 